\title{
Probiotic Lactobacilli Improved Growth Performance and Attenuated Salmonella Typhimurium Infection Via Jak/Stat Signaling in Broilers
}

http://dx.doi.org/10.1590/1806-9061-2020-1328

\section{-Author(s)}

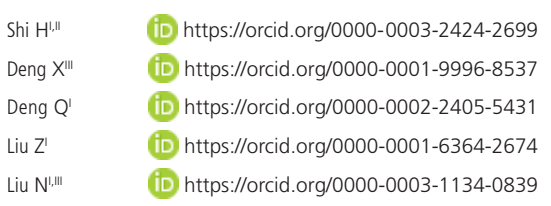

Department of Animal Science, Henan University of Science and Technology, Luoyang 471023, China.

" Department of Poultry Science, University of Georgia, Athens 30602, GA, USA

III National Engineering Research Center of Biological Feed, Beijing 100081, China.

\section{nail Address}

Corresponding author e-mail address Ning Liu

Room 525, Dongke Building, Kaiyuan Ave. No. 263, Luolong District, Luoyang 471023 , China.

Phone: +86 37964282341

Email: ningliu68@163.com

\section{aKeywords}

IFNy; interleukin; Salmonella Typhimurium load; TNF $\alpha$.

\section{ABSTRACT}

This study aimed to investigate the effect of Lactobacillus plantarum DPP8 and Lactobacillus acidophilus C7282 in feed supplementation on growth performance, Salmonella invasion, inflammation, and mediating signaling in broilers infected with Salmonella Typhimurium (S. Typhimurium). A total of 240 broilers at day old were randomly allocated into four groups, orally infected with S. Typhimurium and supplemented with individual or combined Lactobacilli DPP8 and C7282 at doses of 0 (control), $10^{10}$ (individual), or $2.0 \times 10^{10}$ (combination) cfu/ $\mathrm{kg}$ of diet for $21 \mathrm{~d}$. The results showed that supplementing Lactobacilli improved $(p<0.05)$ feed intake and body weight gain and decreased $(p<0.05)$ S. Typhimurium load in the caecum, harder gland, spleen and bursa of Fabricius. Also, the supplements decreased $(p<0.05)$ interleukin (1//2/4), tumor necrosis factor $\alpha$ and interferon $\gamma$ in the serum, enhanced $(p<0.05)$ interleukin 10 , and downregulated gene expressions of inflammatory mediators including Janus kinase (Jak2/3), signal transducer and activator of transcription protein (STAT3/4/5/6) in the intestinal mucosa. In contrast, diets containing DPP8 exhibited greater effects on the inhibition of the pathogen and inflammatory response than $\mathrm{C} 7282$. The obtained data suggest that Lactobacilli C7282 and DPP8 can be used as feed additives to inhibit colonization and translocation of S. Typhimurium and inflammatory responses via downregulating Jak/STAT signaling in broilers.

\section{INTRODUCTION}

Salmonella infection is one of the world's most leading epidemic diseases and poses a great threat to animal production and public health (Dar et al., 2017; Chen et al., 2018). Poultry, a primary source for this foodborne diseases, is most susceptible to Salmonella strains especially Salmonella Typhimurium (S. Typhimurium) (Ding et al., 2018; Liu et al., 2019). With the prohibition of growth-promoting antibiotics in many countries, probiotic administration is an effective strategy to cope with pathogenic infections with few side-effects and a high safety profile (Plaza-Diaz et al., 2019; Zhao et al., 2020a,b; Shi et al., 2020). Lactobacilli has long been used as a health-promoting agent in prevention or treatment of enteric infection and inflammatory diseases and its possible action mechanisms are involved in the modulation of intestinal barrier, defensin, lactic acid production and interactions with hosts and pathogens during inflammatory initiation and progress (Liu et al., 2017, 2018a,c; Wang et al., 2019a; Deng et al., 2020a,b).

Janus kinase/signal transduction and activator of transcription (Jak/ STAT) signaling pathway is implicated in the pathogenesis of inflammatory and autoimmune diseases via many cytokines to transduce intracellular signals to combat inflammatory process (Xin et al., 2020). Lactobacillus rhamnosus GG elevated gut epithelial leptin levels which acted as a 
chemokine to promote cell proliferation through the upregulation of Jak/STAT pathway in mice (Darby et al., 2019), but the probiotic strain deregulated Jak/ STAT, mitogen-activated protein kinase, nuclear factor$\kappa \mathrm{B}$, and tumor necrosis factor in $\mathrm{H}_{2} \mathrm{O}_{2}$-induced Caco2 cells (Hou et al., 2019). Lactobacillus plantarum Lp-1s induced interferon- $\beta$, stimulated STAT1 phosphorylation and activated nuclear translocation of p-STAT1 in intestinal porcine enterocytes (Wang et al., 2019b). Lactobacillus rhamnosus GR-1 induced IL10 production in human placental trophoblast cells and involves activation of Jak/STAT and mitogen-activated protein kinase pathways (Yeganegi et al., 2010). However, information about probiotics on Jak/STAT signal in farm animals is mostly unclear.

The present study aimed to test the hypothesis that probiotic Lactobacillus acidophilus C7282 and L Lactobacillus plantarum DPP8 can attenuate $S$. Typhimurium infection by inhibiting its colonization and translocation as well as modulating inflammatory mediators via Jak/STAT signaling in broilers.

\section{MATERIALS AND METHODS}

\section{Ethics statement}

The trial protocol was approved by the Institutional Committee for Animal Use and Ethics of the College of Animal Science in Henan University of Science and Technology (No. 2018016).

\section{Bacterial strains, diets and treatments}

Lactobacillus acidaphilus CGMCC7282 (C7282) was isolated from the feces of swine and obtained from China General Microbiological Culture Collection Center (Beijing, China). Lactobacillus plantarum CCTCC M2016136 DPP8 (DPP8) from the intestine of grass carp was reserved in China Center for Type Culture Collection (Wuhan, China). Lyophilized C7282 and DPP8 were recovered and aerobically enriched in De Man, Rogosa and Sharpe (MRS) broth (HB03841; Qingdao Hopebio Co. Ltd., Shandong, China) at $37^{\circ} \mathrm{C}$ for $48 \mathrm{~h}$. After bacterial enumeration, the broth loaded C7282 or DPP8 was sprayed onto corn powder (40 meshes) using a step-by-step method and was added at 0 (control), $10^{10}$ (C7282), $10^{10}$ (DPP8) and $2.0 \times 10^{10}$ (combined C7282 and DPP8 at 1:1 ratio) colony forming units $(\mathrm{cfu}) / \mathrm{kg}$ at the expense of corn in a basal diet (Table 1). S. Typhimurium (Salmonella enterica subsp. enterica serovar Typhimurium) SL1344 was grown overnight at $37^{\circ} \mathrm{C}$ in Rappaport-Vassiliadis Medium (RVM, HB4092; Qingdao Hopebio) for the establishment of animal model. Four treatments consisted of the control with $S$. Typhimurium infection, and based on the control C7282 or DPP8 was added at individual or combination as described above.

Table 1 - Ingredient and nutrition levels of basal diet $(\mathrm{g} / \mathrm{kg}$, as fed basis).

\begin{tabular}{lccc}
\hline Ingredient & Content & Composition* $^{*}$ & Content \\
\hline Corn & 580 & Crude protein & 210.5 \\
Soybean meal & 278 & ME, MJ/kg & 12.6 \\
Corn gluten meal & 60 & Crude fiber & 26.3 \\
Soybean oil & 30 & Lysine & 12.4 \\
Met & 2 & Met & 5.5 \\
Lys & 3 & Met + Cys & 8.7 \\
Salt & 4 & Ca & 10.1 \\
Limestone & 18 & Non-phytate P & 4.8 \\
\hline Dicalcium phosphate & 15 & & \\
Premix & 10 & & \\
\hline
\end{tabular}

${ }^{*}$ Calculated by Chinese Feed Database, version 25, 2014.

** The premix provided the following per $\mathrm{kg}$ of diets: vitamin $\mathrm{A}$ (retinyl acetate), 9,000 IU; cholecalciferol, 4,000 IU; vitamin E (DL-tocopheryl acetate), $50 \mathrm{IU}$; vitamin K, 2 mg; thiamin, 2 mg; riboflavin, 5 mg; d-pantothenic acid, $15 \mathrm{mg}$; niacin, 40 mg; pyridoxine, $2 \mathrm{mg}$; biotin, $0.1 \mathrm{mg}$; folic acid, $0.55 \mathrm{mg}$; vitamin B12, $0.01 \mathrm{mg}$; manganese, $120 \mathrm{mg}$; iodine, $1.2 \mathrm{mg}$; iron, $40 \mathrm{mg}$; copper, $16 \mathrm{mg}$; zinc, $100 \mathrm{mg}$; and selenium, $0.3 \mathrm{mg}$.

\section{Animal management and sample collection}

A total of 240 male Arbor Acres broilers (negative for $S$. Typhimurium by rectal swab detection) at day old were randomly assigned into four groups with 6 replicates of 10 broilers each in responding to the four treatments. All broilers were raised in battery cages and had free access to the respective experimental diets and water for $21 \mathrm{~d}$. Feed consumption and mortality were recorded daily. Average daily feed intake (ADFI), average daily body weight gain (ADG), and feed conversion ratio (FCR, ADFI/ADG) were calculated based on a replicate basis. On the first day of the feeding trial, each broiler was orally garaged with $1 \mathrm{~mL}$ of $10^{3} \mathrm{cfu}$ of $\mathrm{S}$. Typhimurium to establish a clinical salmonellosis model (Liu et al., 2019).

On the $21^{\text {st }} \mathrm{d}$ post administration, 6 broilers per replicate were randomly collected for blood sampling from the heart and then euthanized using $\mathrm{CO}_{2}$ and dissected. The serum was prepared by centrifuging at $1,000 \times \mathrm{g}$ for $10 \mathrm{~min}$ (Liu et al., 2018b) and stored at $-20^{\circ} \mathrm{C}$ for the analysis of cytokines. Approximately 5 $\mathrm{g}$ of caecal content, caecal tonsils, liver, spleen, bursa of Fabricius, left thymus, harder gland, bone marrow from the left femurs were collected and stored at -40 ${ }^{\circ} \mathrm{C}$ for the enumeration of S. Typhimurium. Caecal mucosa was collected and stored in RNAlater for mRNA assay. 


\section{Bacterial enumeration and biochemical assay}

For enumeration of C7282, DPP8, and S. Typhimurium, each sample was homogenized, weighed, and diluted at 1:10 (wt/vol) with phosphate buffered saline (pH 7.2) and mixed thoroughly (Liu et al., 2018d). The suspension of each sample was serially diluted between $10^{-1}$ to $10^{-7}$ dilutions, and $100 \mu \mathrm{L}$ of each diluted sample was spread in triplicate onto agars (MRS for C7282 and DPP8; RVM for S. Typhimurium) at 37 ${ }^{\circ} \mathrm{C}$ for $24 \mathrm{~h}$. The amount of bacteria was expressed as a logarithmic $\left(\log _{10}\right)$ transformation per gram of sample.

Chicken enzyme-linked immunosorbent assay kits from Cusabio Technology LLC (Distributor in Wuhan, China) were used for the detection of cytokines according to manuals, including interleukin (IL)-1 $\beta$ (IL1 $\beta$; 073909); IL2 (O73883); IL4 (Q5W4U1); IL6 (Q90YI0); IL8 (P08317); IL10 (Q6A2H4), tumor necrosis factor- $\alpha$ (TNF $\alpha$; CSB-E11231Ch) and interferon- $\gamma$ (IFN $\gamma$; CSB-E08550Ch).

Tissue mRNA isolation and CDNA synthesis were carried out using kits from TaKaRa Co. (Dalian, China) according to manuals. Random hexamers and RNase inhibitor were utilized in the reaction. Controls without reverse transcriptase were included for the genomic DNA contamination check. The mRNA level was expressed as 2- ${ }^{\Delta \Delta C t}$ using a housekeeping gene as a reference (Livak and Schmittgen, 2001). SYBR Green Master Mix (TaKaRa) was used for qPCR reactions by $A B I$ PRISM ${ }^{\circledR} 7900 H T$ Sequence Detection System (Applied Biosystems, Foster City, CA, USA). The qPCR reactions were set at $10 \mu \mathrm{L}$ with $5 \mu \mathrm{L}$ of SYBR, $1 \mu \mathrm{L}$ of primer (Table 2), $4 \mu \mathrm{L}$ of $10 \times$ diluted cDNA. The conditions of the two-step qPCR were set as follows: activation for $3 \mathrm{~min}$ at $95^{\circ} \mathrm{C}$ followed by 40 cycles of $15 \mathrm{~s}$ at $95^{\circ} \mathrm{C}$ and $1 \mathrm{~min}$ at $60^{\circ} \mathrm{C}$.

Table 2 - Information of primers for quantitative real-time PCR.

\begin{tabular}{|c|c|c|c|c|}
\hline \multirow[b]{2}{*}{ Names } & \multirow[b]{2}{*}{ GenBank } & \multicolumn{2}{|l|}{ Primers $\left(5^{\prime} \rightarrow 3^{\prime}\right)$} & \multirow{2}{*}{$\begin{array}{l}\text { Length } \\
\text { (bp) }\end{array}$} \\
\hline & & Forward & Reverse & \\
\hline Jak1 & NM_204870.1 & gagccagacacgagttaccc & agcttcaatgcacagctcct & 269 \\
\hline Jak2 & NM_001030538.2 & gtgccgtgcatggagagg & ctgtctgcttgggtgcacta & 273 \\
\hline Jak3 & NM_204996.3 & acagcttcctcacccgaaag & tagacacgtggatggcgatg & 192 \\
\hline STAT1 & NM_001012914.1 & cccaagggaaacggctacatt & gctctacctttacgccgtgt & 186 \\
\hline STAT3 & NM_001030931.2 & taagctctgcagctccttcc & tcgctgtaaagctggtggag & 237 \\
\hline STAT4 & NM_001267555.1 & agggaccactcgtacagcat & ggatgcagcctcccaatctt & 159 \\
\hline STAT5 & AF074248.1 & gaagtgctgactccaaacggg & gttgtcgaggtcgatggagt & 299 \\
\hline STAT6 & XM_025145654.1 & gccgatatggtgacggagaa & cctctcgcagcgctttatct & 180 \\
\hline GAPDH & NM_204305.1 & gggcacgccatcactatctt & tcacaaacatgggggcatca & 187 \\
\hline
\end{tabular}

GAPDH, glyceraldehyde-3-phosphate dehydrogenase; Jak, Janus kinase; STAT, signal transducer and activator of transcription.

\section{Statistical analysis}

Data are represented as mean and SEM using SPSS software (IBM SPSS, version 23, Armonk, NY, USA). Statistical unit was the average mean of all broilers per replicate for growth performance and of 6 dissected broilers per replicate for tissue detection. Differences between mean values of normally distributed data were assessed by Tukey'b-test of one-way ANOVA at $p<0.05$ level of significance, and Tamhane's T2 test for parameters with heterogeneity variance.

\section{RESULTS}

\section{load \\ Growth performance and S. Typhimurium}

During feeding trial, broilers with $S$. Typhimurium administration experienced mild symptoms like depression, diarrhea, dehydration and general weakness. On the $21^{\text {st }} \mathrm{d}$ post administration, the broilers in the control treatment showed worse $(p<0.05)$ ADFI and ADG, whereas these parameters were recovered $(p<0.05)$ by individual or combined C7282 and DPP8 addition, but there were no differences among the three treatments in growth performance (Table 3 ). Mortality of the control treatment was greater $(p<0.05)$ than that of the other treatments.

The present study further investigated the colonization and translocation of $S$. Typhimurium (Table 4), finding that the three supplemental treatments decreased $(p<0.05)$ the pathogen population in caecum, tonsils, harder gland, bursa and spleen, and the decreasing effects of diets containing DPP8 in the caecum and tonsils were more pronounced $(p<0.05)$ than $C 7282$ 
Table 3 - Effect of Lactobacilli on the growth performance of broilers from 1 to 21 days of age.

\begin{tabular}{|c|c|c|c|c|c|c|}
\hline \multirow{2}{*}{ Item } & \multicolumn{4}{|c|}{ Salmonella Typhimurium infection } & \multirow{2}{*}{ SEM } & \multirow{2}{*}{$p$-value } \\
\hline & Control & C7282 & DPP8 & Combination & & \\
\hline \multicolumn{7}{|c|}{ Growth performance } \\
\hline ADFI, g/bird & $37.47^{b}$ & $39.48^{a}$ & $39.82^{a}$ & $40.11^{a}$ & 0.215 & $<0.001$ \\
\hline ADG, g/bird & $54.92^{b}$ & $56.99^{a}$ & $57.29^{a}$ & $58.28^{a}$ & 0.415 & $<0.001$ \\
\hline FCR & $1.466^{a}$ & $1.444^{\mathrm{a}}$ & $1.439^{a}$ & $1.453^{\mathrm{a}}$ & 0.012 & 0.441 \\
\hline Mortality, \% & $6.67^{a}$ & $1.67^{b}$ & $2.50^{\mathrm{b}}$ & $1.67^{b}$ & 1.070 & 0.010 \\
\hline
\end{tabular}

a-b Means with different superscripts within the same row are different $(p<0.05)$.

ADFI, average daily feed intake; ADG, average daily body weight gain; Combination, C7282 + DPP8; C7282, Lactobacillus acidophilus CGMCC7282; DPP8, Lactobacillus plantarum DPP8; FCR, feed conversion ratio, ADFI/ADG.

alone. In thymus and bone marrow, there were no significant decreases in $S$. Typhimurium loads by the three supplements, but in the liver it was decreased $(p<0.05)$ by DPP8. The findings indicate that individual or combined C7282 and DPP8 can attenuate the negative effect of $S$. Typhimurium infection on the growth performance by inhibiting the colonization and translocation in broilers.

Table 4 - Effect of Lactobacilli on the Salmonella Typhimurium load of broilers.

\begin{tabular}{|c|c|c|c|c|c|c|}
\hline \multirow{2}{*}{ Item } & \multicolumn{4}{|c|}{ Salmonella Typhimurium infection } & \multirow{2}{*}{ SEM } & \multirow{2}{*}{$p$-value } \\
\hline & Control & C7282 & DPP8 & Combination & & \\
\hline \multicolumn{7}{|c|}{ Salmonella Typhimurium load, $\log _{10} \mathrm{cfu} / \mathrm{g}$} \\
\hline Caecal content & $4.603^{a}$ & $3.106^{b}$ & $2.647^{c}$ & $2.550^{c}$ & 0.076 & $<0.001$ \\
\hline Caecal tonsil & $0.420^{\mathrm{a}}$ & $0.352^{b}$ & $0.273^{c}$ & $0.291^{c}$ & 0.010 & $<0.001$ \\
\hline Harder gland & $0.234^{a}$ & $0.089^{b}$ & $0.092^{b}$ & $0.080^{b}$ & 0.006 & $<0.001$ \\
\hline Thymus & $0.149^{a}$ & $0.134^{a}$ & $0.120^{a}$ & $0.119^{a}$ & 0.008 & 0.056 \\
\hline Liver & $0.065^{\mathrm{a}}$ & $0.053^{\mathrm{ab}}$ & $0.041^{b}$ & $0.050^{\mathrm{ab}}$ & 0.005 & 0.030 \\
\hline Spleen & $0.404^{a}$ & $0.214^{b}$ & $0.197^{b}$ & $0.186^{b}$ & 0.007 & $<0.001$ \\
\hline Bursa of Fabricius & $0.180^{a}$ & $0.091^{b}$ & $0.083^{b}$ & $0.079^{b}$ & 0.007 & $<0.001$ \\
\hline Bone marrow & $0.032^{a}$ & $0.027^{a}$ & $0.025^{a}$ & $0.018^{a}$ & 0.007 & 0.494 \\
\hline
\end{tabular}

a-cMeans with different superscripts within the same row are different $(p<0.05)$.

Combination, C7282 + DPP8; C7282, Lactobacillus acidophilus CGMCC7282; DPP8, Lactobacillus plantarum DPP8.

\section{Cytokines induced by $S$. Typhimurium}

Broilers in the control group had greater $(p<0.05)$ serum levels of IL $1 \beta / 2 / 4 / 6$, TNF $\alpha$, and IFN $\gamma$, whereas these parameters were decreased $(p<0.05)$ by individual or combined C7282 and DPP8 (Table 5). Combined Lactobacilli exhibited greater decreases $(p<0.05)$ in IL1 $\beta / 8$ than C7282. IL10 was increased $(p<0.05)$ only by combination treatment compared to the control. These findings indicate that the probiotic can attenuate the inflammatory response induced by S. Typhimurium in broilers.

\section{Jak/STAT signaling induced by $S$. Typhimurium}

The addition of individual or combined C7282 and DPP8 downregulated $(p<0.05)$ the mRNA levels of Jak2/3 and STAT3/4/5/6 in the intestinal mucosa compared to the control (Table 6). Diets containing DPP8 showed decreasing effects $(p<0.05)$ on Jak 1

Table 5 - Effect of Lactobacilli on serum cytokines $(\mathrm{pg} / \mathrm{mL})$ of broilers.

\begin{tabular}{|c|c|c|c|c|c|c|}
\hline \multirow{2}{*}{ Item } & \multicolumn{4}{|c|}{ Salmonella Typhimurium infection } & \multirow{2}{*}{ SEM } & \multirow{2}{*}{$p$-value } \\
\hline & Control & C7282 & DPP8 & Combination & & \\
\hline IL-1 $\beta$ & $202.3^{a}$ & $125.1^{\mathrm{b}}$ & $106.8^{\mathrm{bc}}$ & $87.71^{\mathrm{c}}$ & 7.737 & $<0.001$ \\
\hline IL-2 & $20.78^{a}$ & $13.90^{\mathrm{b}}$ & $12.74^{b}$ & $11.39^{b}$ & 6.765 & $<0.001$ \\
\hline |L-4 & $177.9^{a}$ & $125.5^{b}$ & $114.9^{b}$ & $106.5^{b}$ & 6.505 & $<0.001$ \\
\hline IL-6 & $152.0^{\mathrm{a}}$ & $144.5^{\mathrm{ab}}$ & $111.4^{b}$ & $109.7^{b}$ & 9.271 & 0.007 \\
\hline IL-8 & $86.57^{a}$ & $75.92^{\mathrm{ab}}$ & $66.87^{\mathrm{bc}}$ & $57.34^{c}$ & 4.129 & 0.001 \\
\hline IL-10 & $39.35^{b}$ & $46.03^{b}$ & $51.49^{b}$ & $83.99^{a}$ & 3.756 & $<0.001$ \\
\hline TNF- $\alpha$ & $124.5^{\mathrm{a}}$ & $90.19^{b}$ & $80.41^{b}$ & $77.68^{b}$ & 5.497 & $<0.001$ \\
\hline INF- $\gamma$ & $77.75^{\mathrm{a}}$ & $51.21^{\mathrm{b}}$ & $43.56^{b}$ & $41.58^{b}$ & 3.776 & $<0.001$ \\
\hline
\end{tabular}

a-dMeans with different superscripts within the same row are different $(p<0.05)$.

Combination, C7282 + DPP8; C7282, Lactobacillus acidophilus CGMCC7282; DPP8, Lactobacillus plantarum DPP8. 
whereas diets containing $C 7282$ reduced $(p<0.05)$ STAT1 compared to the control. For Jak2, treatments DPP8 and combination showed a more pronounced decrease $(p<0.05)$ than $\quad 7282$, but there was no difference between treatments DPP8 and combination.

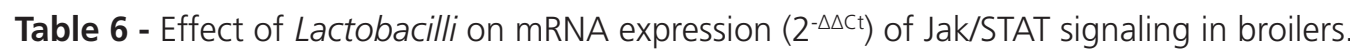

\begin{tabular}{|c|c|c|c|c|c|c|}
\hline \multirow{2}{*}{ Item } & \multicolumn{4}{|c|}{ Salmonella Typhimurium infection } & \multirow{2}{*}{ SEM } & \multirow{2}{*}{$p$-value } \\
\hline & Control & C7282 & DPP8 & Combination & & \\
\hline Jak1 & $0.702^{\mathrm{a}}$ & $0.610^{\mathrm{ab}}$ & $0.593^{b}$ & $0.557^{b}$ & 0.025 & 0.009 \\
\hline Jak2 & $0.607^{a}$ & $0.349^{b}$ & $0.293^{c}$ & $0.255^{c}$ & 0.015 & $<0.001$ \\
\hline Jak3 & $0.664^{a}$ & $0.513^{b}$ & $0.472^{b}$ & $0.441^{b}$ & 0.019 & $<0.001$ \\
\hline STAT1 & $0.476^{a}$ & $0.384^{b c}$ & $0.429^{a b}$ & $0.344^{c}$ & 0.017 & 0.002 \\
\hline STAT3 & $0.710^{\mathrm{a}}$ & $0.587^{b}$ & $0.568^{b}$ & $0.547^{b}$ & 0.017 & 0.001 \\
\hline STAT4 & $0.721^{\mathrm{a}}$ & $0.603^{b}$ & $0.595^{b}$ & $0.594^{b}$ & 0.025 & 0.013 \\
\hline STAT5 & $0.628^{a}$ & $0.486^{b}$ & $0.503^{b}$ & $0.457^{b}$ & 0.013 & 0.001 \\
\hline STAT6 & $0.641^{\mathrm{a}}$ & $0.430^{\mathrm{b}}$ & $0.457^{b}$ & $0.415^{b}$ & 0.024 & $<0.001$ \\
\hline
\end{tabular}

a-cMeans with different superscripts within the same row are different $(p<0.05)$.

Combination, C7282 + DPP8; C7282, Lactobacillus acidophilus CGMCC7282; DPP8, Lactobacillus plantarum DPP8; Jak, Janus kinase; STAT, signal transducer and activator of transcription.

\section{DISCUSSION}

Poultry is the primary source of typical or nontypical Salmonella outbreaks due to rapidly growing from genetic and feeding practices. In the present study, broilers in the control treatment with Salmonella infection showed worse growth performance and the greatest load of $S$. Typhimurium, but these were significantly reversed by supplemental Lactobacilli. In laying hens, Upadhaya et al. (2016) reported that probiotics decreased intestinal and fecal Salmonella counts, whereas Adhikari et al. (2019) found that Salmonella was the lowest in the ovary and the highest in the spleen, however, probiotics did not cause statistical differences in the internal organ loads among the treatments. Additionally, the reduction of $S$. Typhimurium in the intestinal colonization by probiotics was related to competition for iron in mice (Deriu et al., 2013). Whether Lactobacilli strains used in the present study inhibit S. Typhimurium through some nutrients deserves further study. Also of note was that the lack of a negative group in the present study did not invalidate the obtained results, but make it not so strong.

In the present study, the effect of probiotics on attenuating inflammatory response is a consequence of inhibiting S. Typhimurium colonization and translocation in the digestive tract and other visceral organs, namely the less pathogen count, the less oxidative stress and inflammatory response. For relationship between probiotics and expression of cytokines in Salmonella-induced chicken models, Hu et al. (2015) reported that Lactobacillus zeae LB1, Lactobacillus plantarum S8 and Lactobacillus reuteri
S64 attenuated lipopolysaccharide-induced TNF factor, IL6, IL8, IL12, IFN $\gamma$ and IL4; Haghighi et al. (2008) argued that only IL12 and IFN $\gamma$ were repressed by Lactobacillus acidophilus, Bifidobacterium bifidum and Streptococcus faecali in chicken intestinal colonization, but not for IL6; Wang et al. (2018) found that Lactobacillus plantarum LTC-113 prevented the increase of inflammatory meditators myeloperoxidase, IL $1 \beta$, IL6 and inflammation scores; and also Lactobacillus based probiotics reduced IL $1 \beta$ and lipopolysaccharideinduced TNF factor (Penha Filho et al., 2015).

The Jak family members are intracellular, nonreceptor tyrosine kinases that transduce cytokine -mediated signals via the Jak/STAT pathway. Jak inhibition is a therapeutic strategy for immune and inflammatory diseases (Schwartz et al., 2017). In the present study, the addition of C7282, DPP8 or their combination downregulated the transcriptional levels of Jak family, which further implicates the antiinflammatory effect of the two probiotics. Similar findings were reported in literature that dietary intake of probiotic kimchi ameliorated IL6 secretion and Jak2 activation in mice (An et al., 2019). Bifidobacterium spp reduced the levels of lipopolysaccharide-induced IL1 and TNF $\alpha$ in macrophage cells (Yeşilova et al., 2012). Probiotic mixture restored phosphorylated Jak2 protein levels to the control condition compared to paclitaxelinduced increase in hybridoma cells (Castelli et al., 2018). However, another probiotic mixture increased Jak2 phosphorylation in the hypothalamus of dietinduced-obese mice (Bagarolli et al., 2017). Therefore, further studies are needed for the effect of Jak2 signal on inflammatory responses induced by pathogens in farm animals. 
Members of STAT protein family are intracellular transcription factors that mediate many aspects of cellular immunity, proliferation, apoptosis and differentiation. STAT1 gene provides instructions for making a protein involved in the generation of Th17 cells and cytokines such as interferon and IL12. STAT3 also mediates cellular responses to a variety of cytokines including IL10/6. Similar with Jak family, STAT1 and STAT3 were deregulated by probiotics in inflammatory models (Bagarolli et al., 2017; Castelli et al., 2018). The literature was consistent with findings in the present study that mRNA levels of STAT3/4/5/6 were also downregulated by individual or combined C7282 and DPP8, and this is also in accordance with the decreases of IL $1 \beta / 2 / 4$, TNF $\alpha$ and IFN $\gamma$ in probiotic treatments.

Interestingly, IL10 was elevated by individual or combined probiotics in the present study, indicating that IL10 acts as an anti-inflammatory cytokine in the S. Typhimurium-induced model. However, Haghighi et al. (2008) and Hu et al. (2008) argued that probiotics reduced or did not affect IL10 expression in Salmonellainduced chickens. Hutchins et al. (2013) found that IL10/STAT3-mediated anti-inflammatory response represented an essential homeostatic mechanism that controlled the degree and duration of inflammation. Furthermore, Kang (2019) reported that STAT3's DNA binding activity was not required for IL10 to inhibit pro-inflammatory gene expression, however, IL10 required STAT3-mediated transcription to enhance antiinflammatory M2 macrophage polarization. Additionally, CD4 ${ }^{+} T$ cells used STAT1 to drive intestinal inflammation and STAT1 played a critical role in shielding $T$ cells from natural-killer-cell-mediated cytotoxicity (Kang, 2019). As such, how probiotics influence the $T$ cell and its subsets via STAT signaling in a S. Typhimurium-induced scenario deserves further study.

As a chain of interactions between proteins in a cell, the Jak/STAT pathway plays a major role in many fundamental processes, including apoptosis and inflammation. Information about the effect of probiotics on Jak/STAT pathway is mainly from in vitro or rodent models, however, literature from farm animals is unavailable. Truong et al. (2017a,b) found that necrotic enteritis induced differential expression of Jak/STAT in the spleen and intestinal mucosa of chickens. Similarly, in the present study, S. Typhimurium induced the expression of Jak/STAT, and importantly, this was reversed by probiotic addition. Paradoxically, IL2 signaling and Jak/STAT signaling were downregulated in response to Salmonella enteritidis infection by the investigation into chicken hepatic global gene expression (Coble et al., 2013). Therefore, the relationship between pathogen-induced Jak/STAT pathway and probiotic protection in farm animals needs further exploration.

It was concluded that supplementing individual or combined C7282 and DPP8 restored growth performance of broilers infected with $S$. Typhimurium, decreased the pathogeniccolonization and translocation in tissues, and attenuated inflammation by influencing cytokines and inflammatory mediators. The effects of diets containing DPP8 were more pronounced than C7282 on elimination of $S$. Typhimurium. The results suggest that C7282 and DPP8 can be used as feed additives to prevent $S$. Typhimurium infection and attenuate inflammatory responses via Jak/STAT signaling blockage in broilers.

\section{ACKNOWLEDGMENTS}

This research was supported by Henan Tackle Key Problem Project (182102110184), Henan Natural Science Foundation (182300410052), and SchoolEnterprise Cooperation Program between HAUST and Luoyang Xintai Agro-pastoral Technology Co., Ltd (22010076).

\section{CONFLICT OF INTEREST}

The authors have no conflicts of interest.

\section{REFERENCES}

Adhikari $\mathrm{P}$, Lee $\mathrm{CH}$, Cosby DE, Cox NA, Kim WK. Effect of probiotics on fecal excretion, colonization in internal organs and immune gene expression in the ileum of laying hens challenged with Salmonella enteritidis. Poultry Science 2019;98:1235-1242.

An JM, Kang EA, Han YM, Oh JY, Lee DY, Choi SH, et al. Dietary intake of probiotic kimchi ameliorated IL-6-driven cancer cachexia. Journal of Clinical Biochemistry and Nutrition 2019;65:109-117.

Bagarolli RA, Tobar N, Oliveira AG, Araújo TG, Carvalho BM, Rocha GZ, et al. Probiotics modulate gut microbiota and improve insulin sensitivity in DIO mice. Journal of Nutritional Biochemistry 2017;50:16-25.

Castelli V, Palumbo P, D'Angelo M, Moorthy NK, Antonosante A, Catanesi $M$, et al. Probiotic DSF counteracts chemotherapy induced neuropathic pain. Oncotarget 2018;9:27998.

Chen S, Liao C, Zhang C, Cheng X. Roles of the crp and sipB genes of Salmonella enterica serovar Typhimurium in protective efficacy and immune responses to vaccination in mice. Canadian Journal of Veterinary Research 2018;82:102-105.

Coble DJ, Sandford EE, Ji T, Abernathy J, Fleming D, Zhou H, et al. Impacts of Salmonella enteritidis infection on liver transcriptome in broilers. Genesis 2013;51:357-364.

Darby TM, Naudin CR, Luo L, Jones RM. Lactobacillus rhamnosus GGinduced expression of leptin in the intestine orchestrates epithelial cell proliferation. Cellular and Molecular Gastroenterology and Hepatology 2020;9:627-639. 
Deriu E, Liu JZ, Pezeshki M, Edwards RA, Ochoa RJ, Contreras $H$, et al. Probiotic bacteria reduce Salmonella Typhimurium intestinal colonization by competing for iron. Cell Host \& Microbe 2013;14:2637.

Dar MA, Ahmad SM, Bhat SA, Ahmed R, Urwat U, Mumtaz PT, et al. Salmonella Typhimurium in poultry: a review. World's Poultry Science Journal 2017;73:345-354.

Deng Q, Shi H, Luo Y, Zhao H, Liu N. Effect of dietary Lactobacilli Mixture on Listeria monocytogenes infection and virulence property in broilers. Poultry Science 2020a;99:3655-3662.

Deng Q, Shi H, Luo Y, Liu N, Deng X. Dietary lactic acid bacteria modulate yolk components and cholesterol metabolism by HMGR pathway in laying hens. Brazilian Journal of Poultry Science 2020b;22(3):1-8.

Ding $\mathrm{K}$, Shang $\mathrm{K}, \mathrm{Yu} Z \mathrm{ZH}$, Yu C, Jia YY, He L, et al. Recombinantattenuated Salmonella Pullorum strain expressing the hemagglutininneuraminidase protein of Newcastle disease virus (NDV) protects chickens against NDV and Salmonella Pullorum challenge. Journal of Veterinary Science 2018;19:232-241.

Haghighi HR, Abdul-Careem MF, Dara RA, Chambers JR, Sharif S. Cytokine gene expression in chicken cecal tonsils following treatment with probiotics and Salmonella infection. Veterinary Microbiology 2008;126:225-233.

Haghighi et al. (2015) shown on page 8 line 217 ----Re: 2015 is a mistake, and 2008 is correct.

Hou Y, Li X, Liu X, Zhang Y, Zhang W, Man C, et al. Transcriptomic responses of Caco-2 cells to Lactobacillus rhamnosus GG and Lactobacillus plantarum $J 26$ against oxidative stress. Journal of Dairy Science 2019;102:7684-7696.

Hu JL, Yu H, Kulkarni RR, Sharif S, Cui SW, Xie MY, et al. Modulation of cytokine gene expression by selected Lactobacillus isolates in the ileum, caecal tonsils and spleen of Salmonella-challenged broilers. Avian Pathology 2015;44:463-469. Hu et al. (2008) shown on page 8 line 216

Hutchins AP, Diez D, Miranda-Saavedra D. The IL-10/STAT3-mediated antiinflammatory response: recent developments and future challenges. Briefings in Functional Genomics 2013;12:489-498.

Kang Y. IL-10 and the JAK-STAT pathway in the regulation of metabolism and mucosal homeostasis [dissertation]. Cambridge (EUA): Harvard University; 2019. Furthermore, Kang (2019) shown on page 8 line 220

Liu N, Deng X, Liang C, Cai H. Effect of broccoli residues fermented with probiotics on the growth performance and health status of broilers challenged with Clostridium perfringens. Brazilian Journal of Poultry Science 2018d;20:625-631.

Liu N, Ding K, Wang J, Deng Q, Gu K, Wang J. Effects of lactic acid bacteria and smectite after aflatoxin B1 challenge on the growth performance, nutrient digestibility and blood parameters of broilers. Journal of Animal Physiology and Animal Nutrition 2018a;102:953-961.

Liu N, Ding K, Wang JQ, Jia SC, Wang JP, Xu TS. Detoxification, metabolism, and glutathione pathway activity of aflatoxin B1 by dietary lactic acid bacteria in broiler chickens. Journal of Animal Science 2017; 95:43994406.

Liu N, Lin L, Wang JQ, Zhang F, Wang JP. Tetramethylpyrazine supplementation reduced Salmonella Typhimurium load and inflammatory response in broilers. Poultry Science 2019;98:3158-3164.

Liu N, Wang JQ, Deng Q, Gu K, Wang JP. Detoxification of aflatoxin B1 by lactic acid bacteria and hydrated sodium calcium aluminosilicate in broiler chickens. Livestock Science 2018b;208:28-32.

Liu N, Wang JQ, Liu Z, Wang Y, Wang JP. Comparison of probiotics and clay detoxifier on the growth performance and enterotoxic markers of broilers fed diets contaminated with aflatoxin B1. Journal of Applied Poultry Research 2018c;27:341-348.
Livak KJ, Schmittgen TD. Analysis of relative gene expression data using realtime quantitative PCR and the $2^{-\Delta \Delta C t}$ method. Methods 2001;25:402408.

Penha Filho RA, Díaz SJ, Fernando FS, Chang YF, Andreatti Filho RL, Junior AB. Immunomodulatory activity and control of Salmonella enteritidis colonization in the intestinal tract of chickens by Lactobacillus based probiotic. Veterinary Immunology and Immunopathology 2015;167:6469.

Plaza-Diaz J, Ruiz-Ojeda FJ, Gil-Campos M, Gil A. Mechanisms of action of probiotics. Advances in Nutrition 2019;10:\$49-66.

Schwartz DM, Kanno Y, Villarino A, Ward M, Gadina M, O'Shea JJ. JAK inhibition as a therapeutic strategy for immune and inflammatory diseases. Nature Reviews Drug Discovery 2017;17:78.

Shi HY, Shi HW, Li Y, Liu N. Effect of lactic acid bacteria on growth performance, oxidative and infectious parameters induced by Listeria monocytogenes in broilers. European Poultry Science 2020;84 Available from: doi:0.1399/eps.2020.316.

Truong $A D$, Rengaraj $D$, Hong $Y$, Hoang $C T$, Hong $Y H$, Lillehoj HS Differentially expressed Jak-STAT signaling pathway genes and target microRNAs in the spleen of necrotic enteritis-afflicted chicken lines. Research in Veterinary Science 2017a;115:235-243.

Truong AD, Rengaraj D, Hong Y, Hoang CT, Hong YH, Lillehoj HS. Analysis of Jak-STAT signaling pathway genes and their microRNAs in the intestinal mucosa of genetically disparate chicken lines induced with necrotic enteritis. Veterinary Immunology and Immunopathology 2017b;187:1-9.

Upadhaya SD, Hossiendoust A, Kim IH. Probiotics in Salmonella-challenged Hy-Line brown layers. Poultry Science 2016;95:1894-1897.

Wang J, Lin L, Jiang Q, Huang W, Liu N. Effect of supplemental lactic acid bacteria on the growth performance, glutathione turnover and aflatoxin B1 removal in lambs. Czech Journal of Animal Science 2019a;64:272-278

Wang J, Lin L, Li B, Zhang F, Liu N. Dietary Artemisia vulgaris meal improved growth performance, gut microbes, and immunity of growing Rex rabbits. Czech Journal of Animal Science 2020;64:174-179.

Wang K, Ran L, Wu D, Yang Y, Xie YI, Yan T, et al. Anti-TGEV miller strain infection effect of Lactobacillus plantarum supernatant based on the JAK-STAT1 signaling pathway. Frontiers in Microbiology. 2019b;10:2540

Wang L, Li L, Lv Y, Chen Q, Feng J, Zhao X. Lactobacillus plantarum restores intestinal permeability disrupted by Salmonella infection in newlyhatched chicks. Scientific Reports 2018;8:2229.

Xin P, Xu X, Deng C, Liu S, Wang Y, Zhou X, et al. The role of JAK/ STAT signaling pathway and its inhibitors in diseases. International Immunopharmacology 2020;80:106210.

Yeganegi M, Leung CG, Martins A, Kim SO, Reid G, Challis JR, et al. Lactobacillus rhamnosus GR-1-induced IL-10 production in human placental trophoblast cells involves activation of JAK/STAT and MAPK pathways. Reproductive Sciences 2010;17:1043-1051.

Yeşilova Y, Çalka Ö, Akdeniz N, Berktaş M. Effect of probiotics on the treatment of children with atopic dermatitis. Annals of Dermatology 2012:24:189-193.

Zhao H, Zhang F, Chai J, Wang J. Effect of lactic acid bacteria on Listeria monocytogenes infection and innate immunity in rabbits. Czech Journal of Animal Science 2020a;65:23-30.

Zhao $\mathrm{H}$, Zhang F, Chai J, Wang J. Lactobacillus acidophilus reduces Listeria monocytogenes infection by inhibiting mitogen-activated protein kinase genes in growing rabbits. Revista Brasileira de Zootecnia. 2020b;49:e20200054. 
